\title{
Desain Inverter Satu Fasa 12V DC ke 220V AC Menggunakan Rangkaian H-Bridge MOSFET
}

\author{
Andhika Giyantara, S.T., M.T. ${ }^{1}$, Risky Susanto Tjiang ${ }^{2}$, Subchan, Ph.D. ${ }^{3}$ \\ ${ }^{1}$ Teknik Elektro, Teknologi Industri dan Proses, Institut Teknologi Kalimantan, Balikpapan. Email: \\ dhika@itk.ac.id \\ ${ }^{2}$ Teknik Elektro, Teknologi Industri dan Proses, Institut Teknologi Kalimantan, Balikpapan. Email: \\ 04141001@itk.ac.id \\ ${ }^{3}$ Matematika, Teknologi Informasi dan Matematika, Institut Teknologi Kalimantan, Balikpapan. \\ Email:subchan@itk.ac.id
}

\begin{abstract}
Inverter is an electronic circuit that convert electric voltage with direct current (DC) to alternating current (AC). One of the commonly used inverter configuration is H-Bridge circuit. Inverter with H-Bridge circuit does not need voltage-balanced diode or capacitor to operate and can be cascaded to obtain multilevel output voltage. H-Bridge circuit works by adjusting the combination of switches that were enabled. One of the commonly used switches is Metal Oxide Semiconductor Field Effect Transistor (MOSFET). The advantages of MOSFET as switching components are its fast switching speed and it did not cause current tail. Therefore, the writing of this paper aims to design a $12 \mathrm{~V}$ DC to $220 \mathrm{~V}$ AC $50 \mathrm{~Hz}$ single-phase inverter with $\mathrm{H}$-Bridge MOSFET circuit. The design stage begins with determining the specifications of the inverter, creating a block diagram of the inverter, determining the required components, and calculating the required parameters of the inverter. The designed inverter is simulated using Proteus 8.4 software. Simulation results are in accordance with the desired specification.
\end{abstract}

Keywords: One phase inverter, H-Bridge MOSFET, Design

\begin{abstract}
Abstrak
Inverter adalah suatu rangkaian elektronika yang berfungsi untuk mengonversikan tegangan listrik dengan arus searah (DC) menjadi tegangan listrik dengan arus bolak-balik (AC). Salah satu konfigurasi inverter yang umum digunakan adalah konfigurasi dengan rangkaian H-Bridge. Keuntungan dari inverter dengan H-Bridge adalah tidak dibutuhkan adanya dioda atau kapasitor penyeimbang tegangan dan rangkaian H-Bridge dapat disusun secara bertingkat untuk mendapatkan tegangan keluaran bertingkat. Rangkaian H-Bridge bekerja dengan dengan mengatur kombinasi sakelar yang diaktifkan. Salah satu komponen sakelar yang umum digunakan adalah Metal Oxide Semiconductor Field Effect Transistor (MOSFET.) Keuntungan MOSFET sebagai komponen sakelar adalah pada kecepatan penyakelarannya yang cepat dan tidak menyebabkan munculnya current tail. Oleh karena itu, penulisan paper ini bertujuan untuk merancang inverter satu fasa $12 \mathrm{~V} \mathrm{DC} \mathrm{ke} 220 \mathrm{~V} \mathrm{AC} 50 \mathrm{~Hz}$ dengan rangkaian H-Bridge MOSFET. Tahap perancangan dimulai dengan menentukan spesifikasi rangkaian inverter, membuat diagram blok rangkaian inverter, menentukan komponen yang dibutuhkan, dan melakukan perhitungan parameter yang diperlukan. Rangkaian inverter disimulasikan dengan software Proteus 8.4. Hasil simulasi telah sesuai dengan spesifikasi yang diinginkan.
\end{abstract}

Kata Kunci: Inverter satu fasa, H-Bridge MOSFET, Perancangan

\section{Pendahuluan}

Inverter adalah rangkaian elektronik yang mengubah tegangan listrik dari arus searah (DC) menjadi arus bolak-balik (AC). Salah satu konfigurasi inverter yang umum digunakan adalah rangkaian H-Bridge. Inverter dengan rangkaian $\mathrm{H}$-Bridge tidak membutuhkan dioda atau kapasitor penyeimbang tegangan dalam rangkaian dan dapat mengalir untuk mendapatkan tegangan keluaran bertingkat. Rangkaian $\mathrm{H}-$ Bridge bekerja dengan mengatur kombinasi sakelar yang diaktifkan. Salah satu sakelar yang umum digunakan adalah Metal Oxide Semiconductor Field Effect Transistor (MOSFET). Keuntungan dari MOSFET sebagai komponen penyakelaran adalah kecepatan penyakelaran cepat dan tidak 
menyebabkan gangguan arus ini. Berdasarkan keunggulan rangkaian H-Bridge dengan menggunakan sakelar MOSFET, makalah ini membahas tentang desain inverter satu fasa dengan rangkaian H-Bridge MOSFET. Inverter ini mengubah energi listrik dari $12 \mathrm{~V}$ DC menjadi $220 \mathrm{~V}$ AC dengan frekuensi $50 \mathrm{~Hz}$ (Bernard, 2014).

\subsection{Rangkaian H-Bridge MOSFET}

Rangkaian MOSFET H-Bridge adalah konfigurasi penyakelaran dari inverter yang terdiri dari empat sakelar, dalam hal ini adalah MOSFET (Metal Oxide Semiconductor Field Effect Transistor), dan disusun menyerupai hurufH, seperti yang ditunjukkan pada Gambar 1. Dengan mengontrol sakelar yang aktif untuk periode waktu tertentu, tegangan yang ada pada beban dapat berupa positif atau negatif (Bernard, 2014).

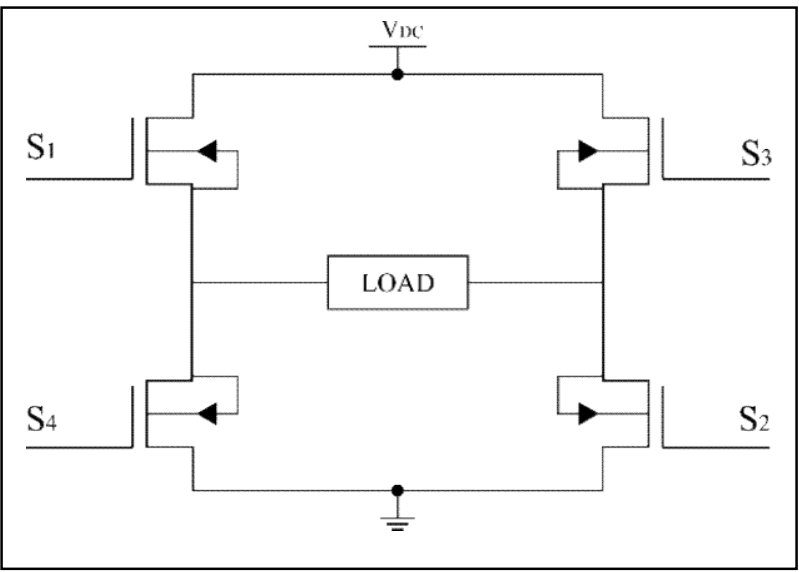

Gambar 1: Rangkaian H-Bridge MOSFET

Sumber: Penulis, 2018

Seperti yang dijelaskan sebelumnya, H-Bridge MOSFET bekerja dengan mengatur sakelar yang aktif selama periode waktu tertentu. Dari Gambar 1, ketika S1 dan S2 diaktifkan, nilai tegangan pada beban bernilai positif. Sedangkan, ketika S3 dan S4 diaktifkan, tegangan pada beban bernilai negatif, seperti yang ditunjukkan pada Gambar 2. Pergantian antara empat sakelar menyebabkan inverter dapat menghasilkan tegangan AC dari sumber tegangan DC (Meghashree, 2016).

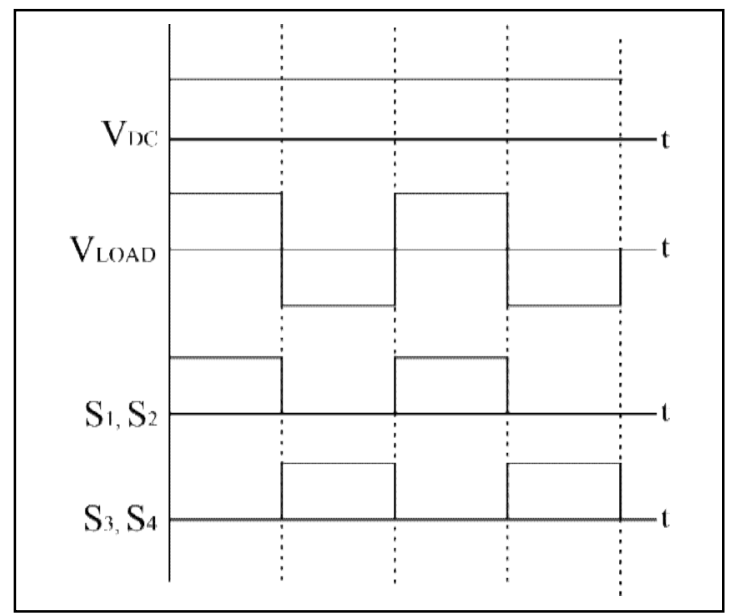

Gambar 2: Gelombang Tegangan pada Inverter H-Bridge MOSFET

Sumber: Penulis, 2018 


\subsection{Rangkaian Penggerak MOSFET}

MOSFET sebagai komponen penyakelaran hanya dapat dioperasikan menggunakan rangkaian penggerak. Rangkaian penggerak MOSFET terdiri dari penggerak MOSFET Integrated Circuit (IC) yang dilengkapi dengan kapasitor dan dioda yang disebut kapasitor bootstrap dan dioda bootstrap, seperti yang ditunjukkan pada Gambar 3 (Bernard, 2014).

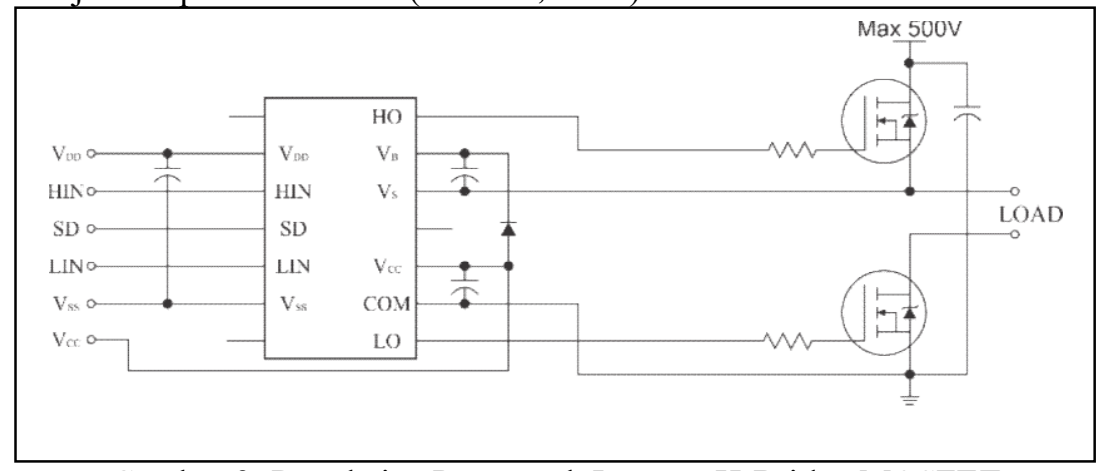

Gambar 3: Rangkaian Penggerak Inverter H-Bridge MOSFET

Sumber: Bernard, 2014

Rangkaian penggerak MOSFET bekerja pada dua kondisi, yaitu sisi rendah dan sisi tinggi. Pada kondisi sisi rendah, sakelar sisi bawah diaktifkan. Pada saat yang sama, kapasitor bootstrap dibebankan melalui dioda bootstrap dari sumber $\mathrm{DC}\left(\mathrm{V}_{\mathrm{CC}}\right)$. Pada kondisi sisi yang tinggi, kapasitor bootstrap akan dilepas dan memberikan tegangan $\mathrm{ke}_{\mathrm{BS}}$. Dioda bootstrap akan memastikan bahwa tidak ada arus dan tegangan mengalir ke $\mathrm{V}_{\mathrm{CC}}$ dan menyebabkan hubung singkat di rangkaian penggerak. Tegangan pada $\mathrm{V}_{\mathrm{BS}}$ mengaktifkan sakelar sisi tinggi. Rangkaian penggerak akan bekerja pada sisi rendah dan kondisi sisi tinggi secara bergantian sesuai dengan sinyal penyakelaran yang diberikan (Fairchild, 2014).

\subsubsection{Kapasitor Bootstrap (Bernard, 2014)}

Untuk menjelaskan nilai magnitude dari kapasitor bootstrap, persamaan 1 dapat digunakan.

$$
C \geq \frac{2\left[2 Q_{g}+\frac{I_{q b s(\max )}}{f_{s}}+Q_{I s}+\frac{I_{C b s(\text { leak })}}{f_{s}}\right]}{V_{d c}-V_{f}-V_{L S}-V_{\min }}
$$

Dimana:

C adalah nilai kapasitansi minimal dari kapasitor bootstrap $(\mathrm{F})$

$\mathrm{Q}_{g}$ adalah gerbang pengisian pada sisi tinggi MOSFET (C)

$\mathrm{f}_{\mathrm{s}}$ adalah frekuensi penyakelaran $(\mathrm{Hz})$

$\mathrm{I}_{\mathrm{Cbs}(\text { leak) }}$ adalah arus bocor pada kapasitor bootstrap (A)

$\mathrm{I}_{\mathrm{qbs}(\max )}$ adalah arus tanpa beban saat $\mathrm{V}_{\mathrm{BS}}$ maksimum (A)

$\mathrm{Q}_{\text {is }}$ adalah nilai tingkat pergeseran pada setiap siklus (C)

$\mathrm{V}_{\mathrm{dc}}$ adalah sumber tegangan DC $(\mathrm{V})$

$\mathrm{V}_{\mathrm{f}}$ adalah tegangan drop forward pada dioda bootstrap (V)

$\mathrm{V}_{\mathrm{LS}}$ adalah tegangan drop pada sisi rendah MOSFET atau beban (V)

$\mathrm{V}_{\text {min }}$ adalah tegangan minimum antara $\mathrm{V}_{\mathrm{B}}$ dan $\mathrm{V}_{\mathrm{S}}(\mathrm{V})$

Kapasitansi yang diperoleh dengan persamaan 1 di atas adalah kapasitansi minimum yang diperlukan. Namun, nilai kapasitansi rendah dapat menyebabkan pengisian yang berlebihan pada kapasitor bootstrap yang dapat merusak IC penggerak MOSFET. Untuk menghindari hal ini, kapasitansi yang diperoleh dikalikan dengan faktor 15 .

\subsubsection{Dioda Bootstrap (Bernard, 2014)}

Untuk menentukan jenis dioda yang digunakan, nilai arus dioda ini diperlukan. Besarnya arus rating dapat dihitung menggunakan persamaan 2 . 


$$
I_{\text {dioder(rating) }} \geq Q_{q} \times f_{s}
$$

Dimana:

$\mathrm{I}_{\text {diode(max) }}$ adalah arus maksimum pada dioda bootstrap (A)

\subsubsection{Gerbang Resistor (Bernard, 2014)}

Ketika MOSFET dioperasikan langsung dari rangkaian penggerak MOSFET dapat menyebabkan penyakelaran berkecepatan tinggi yang tidak diinginkan. Untuk mengatasi masalah ini, gerbang resistor diatur secara seri dengan keluaran rangkaian penggerak MOSFET. Untuk menentukan besarnya gerbang resistor dapat dilakukan berdasarkan kurva yang ditunjukkan pada Gambar 4. Semakin besar nilai gerbang resistor, semakin berkurang nilai amplitude pada tegangan lonjakan negatif, sementara waktu turn-off dari MOSFET akan naik secara linear.

\subsection{Sinusoidal Pulse Width Modulation (SPWM)}

Sinusoidal Pulse Width Modulation (SPWM) adalah teknik yang menggunakan variasi gelombang sinusoidal dengan siklus (d) pada interval penyakelaran (Ts) dan dapat menyebabkan pergeseran harmonisa ke daerah frekuensi yang lebih tinggi. Inverter dengan menggunakan teknik SPWM dapat dibagi menjadi dua jenis, yaitu jembatan analog inverter SPWM dan jembatan digital inverter SPWM (Santos, 2015).

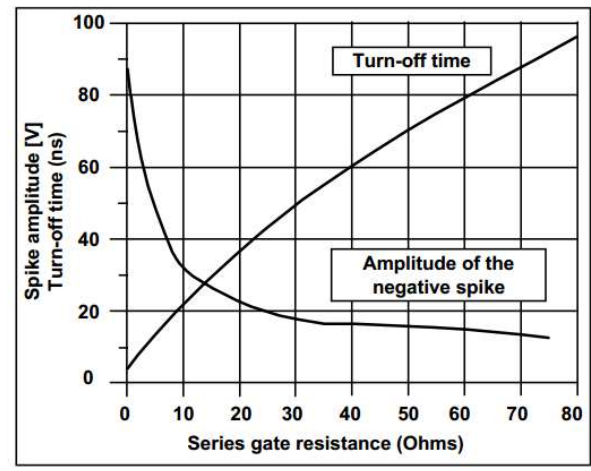

Gambar 4: Kurva Perbandingan antara Gerbang Tahanan, Amplitudo Tegangan Lonjakan Negatif dan Waktu On-OFF MOSFET

Sumber: Bernard, 2014

\subsubsection{Jembatan Analog Inverter SPWM}

Pada jembatan analog inverter SPWM, sinyal SPWM dihasilkan dengan membandingkan dua sinyal referensi, yaitu sinyal modulasi dalam bentuk gelombang sinusoidal dan sinyal pembawa dalam bentuk gelombang segitiga, menggunakan pembanding. Rangkaian untuk jembatan analog inverter SPWM ditunjukkan pada Gambar 5 dan bentuk gelombang tegangan keluaran inverter ditunjukkan pada Gambar 6 (Santos, 2015).

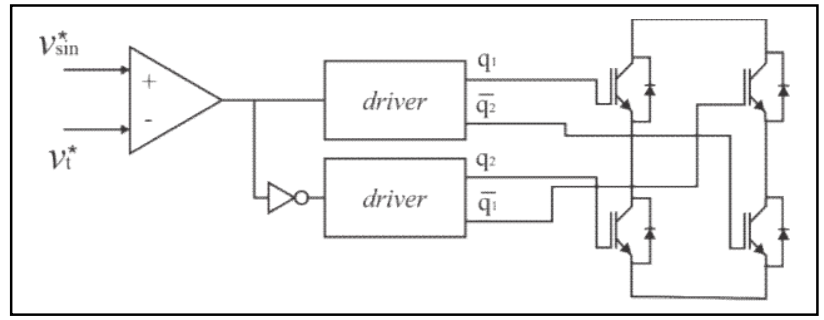

Gambar 5: Rangkaian Jembatan Analog Inverter SPWM

Sumber: Santos, 2015 


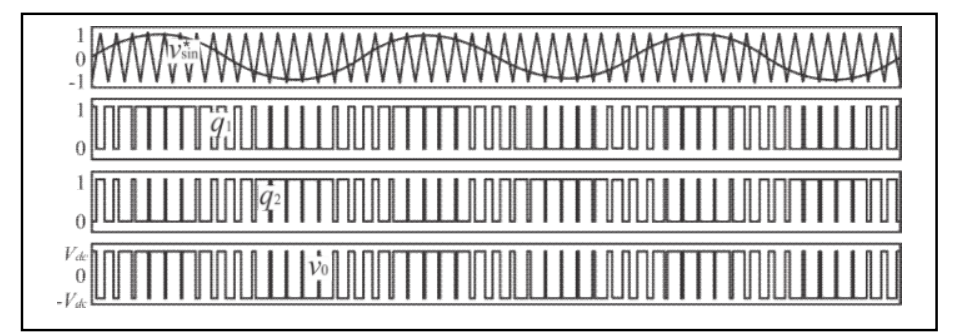

Gambar 6: Gelombang Tegangan Keluaran Jembatan Analog Inverter SPWM Sumber: Santos, 2015

Pada Gambar 5 dan 6, ada dua sinyal SPWM yang dihasilkan dari komparator, yaitu $\mathrm{q}_{1}$ dan $\mathrm{q}_{2}$. Sinyal ini diperlukan karena ketika $\mathrm{q}_{2}$ memiliki bentuk gelombang yang sama dengan $\mathrm{q}_{1}$, maka saklar $\mathrm{q}_{1}$ dan $\mathrm{q}_{2}$ diaktifkan pada saat yang sama dan menyebabkan hubung singkat dalam inverter. Untuk mencegahnya, bentuk gelombang $\mathrm{q}_{2}$ harus ditetapkan sebagai kebalikan dari gelombang $\mathrm{q}_{1}$ menggunakan logika NOT seperti yang ditunjukkan pada Gambar 5. Dari Gambar 6, tegangan output inverter memiliki bentuk gelombang yang sama dengan $\mathrm{q}_{1}$ dengan amplitudo puncak ke puncak $2 \mathrm{~V}_{\mathrm{dc}}$.

Pada jembatan analog di inverter SPWM, frekuensi sinyal modulasi ditentukan berdasarkan frekuensi keluaran yang diinginkan. Jika frekuensi keluaran yang diinginkan adalah $50 \mathrm{~Hz}$, frekuensi sinyal modulasi diatur ke nilai yang sama dengan frekuensi keluaran yang diinginkan, yaitu $50 \mathrm{~Hz}$. Frekuensi sinyal pembawa ditentukan oleh frekuensi maksimum penyaklaran dari komponen saklar yang digunakan dalam inverter. Semakin besar frekuensi sinyal pembawa, semakin halus gelombang tegangan keluaran. Namun, frekuensi yang lebih besar dapat menyebabkan peningkatan suhu operasi saklar yang akan menyebabkan penurunan nilai tegangan pada keluaran inverter. Jadi memilih frekuensi yang tepat dari sinyal pembawa menjadi salah satu faktor penting dalam merancang sebuah inverter (Bernard, 2014).

\subsubsection{Jembatan Digital Inverter SPWM}

Jembatan digital inverter SPWM juga dikenal sebagai inverter berbasis mikrokontroler karena menggunakan mikrokontroler untuk menghasilkan sinyal SPWM secara digital. Inverter jenis ini menyederhanakan rangkaian yang ada di jembatan analog inverter SPWM dengan mengganti sinyal modulasi generator, sinyal pembawa generator, dan pembanding menggunakan mikrokontroler. Sinyal SPWM yang dihasilkan dari jembatan digital inverter SPWM memiliki karakteristik yang sama dengan sinyal SPWM dari jembatan analog inverter SPWM. Amplitudo sinyal SPWM yang dihasilkan akan memiliki besaran yang sama dengan tegangan operasi mikrokontroler yang digunakan (Bernard, 2014).

\subsection{Transformer}

Transformer adalah komponen pasif yang mengubah amplitudo tegangan alternating current (AC) pada kumparan primer transformer menjadi lebih besar atau lebih kecil dari kumparan sekunder. Nilai tegangan dan arus sekunder dari transformer bergantung pada ratio antara jumlah lilitan kumparan primer dan sekunder. Perbandingan antara lilitan kumparan primer dan sekunder ditunjukkan dalam persamaan 3 (Fadhli, 2010).

$$
\frac{N_{p}}{N_{s}}=\frac{V_{p}}{V_{s}}=\frac{I_{s}}{I_{p}}=a
$$

Dimana:

$\mathrm{N}_{\mathrm{p}}$ adalah jumlah lilitan kumparan primer (lilitan)

$\mathrm{N}_{\mathrm{s}}$ adalah jumlah lilitan kumparan sekunder (lilitan)

$\mathrm{V}_{\mathrm{p}}$ adalah tegangan primer transformer $(\mathrm{V})$

$\mathrm{V}_{\mathrm{s}}$ adalah tegangan sekunder transformer $(\mathrm{V})$

$\mathrm{I}_{\mathrm{p}}$ adalah arus primer transformer $(\mathrm{A})$

$\mathrm{I}_{\mathrm{s}}$ adalah arus sekunder transformer (A)

$a$ adalah ratio perbandingan transformer 


\subsection{Low Pass Filter (LPF)}

Low Pass Filter (LPF) adalah rangkaian filter sinyal dimana sinyal dengan frekuensi dibawah frekuensi cut-off dapat melewati dan akan melemahkan sinyal dengan frekuensi yang lebih tinggi dari frekuensi cut-off. LPF adalah filter pasif yang menggunakan komponen seperti resistor (R), induktor (L), dan kapasitor (C) (Panggabean, 2017).

Salah satu rangkaian LPF yang paling umum yaitu filter LC. Filter LC adalah filter LPF yang menggunakan induktor (L) dan kapasitor (C) yang dipasang secara paralel, seperti pada Gambar 7 . Frekuensi cut-off dari filter LC dapat diperoleh menggunakan persamaan 4.

$$
f_{c}=\frac{1}{2 \pi \sqrt{L C}}
$$

Dimana:

$\mathrm{f}_{\mathrm{c}}$ adalah frekuensi cut-off $(\mathrm{Hz})$

$\mathrm{L}$ adalah induktansi dari induktor $(\mathrm{H})$

$\mathrm{C}$ adalah kapasitansi dari kapasitor $(\mathrm{F})$

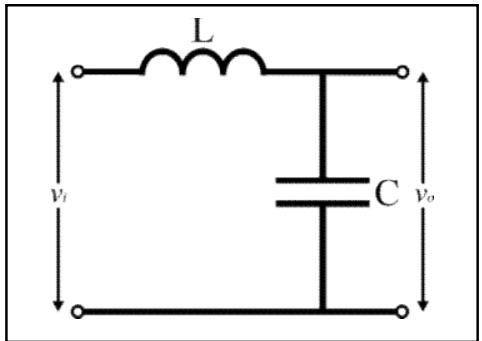

Gambar 7: Filter LC

Sumber: Penulis, 2018

\section{Metode}

Tahap desain dimulai dengan menentukan spesifikasi inverter satu fasa, membuat diagram blok inverter, menentukan komponen yang diperlukan, dan menghitung parameter yang diperlukan. Setelah semua parameter yang diperlukan telah ditentukan, inverter satu fasa akan disimulasikan menggunakan perangkat lunak Proteus 8.4. Hasil simulasi akan dibandingkan dengan nilai ideal yang ditentukan dalam spesifikasi inverter.

\subsection{Spesifikasi Inverter Satu Fasa}

Spesifikasi yang ditentukan untuk inverter satu fasa ditunjukkan pada Tabel 1.

Tabel 1: Spesifikasi inverter satu fasa yang didesain

\begin{tabular}{ll}
\hline \multicolumn{1}{c}{ Spesifikasi } & \multicolumn{1}{c}{ Kondisi } \\
\hline Kanstruksi & H-Bridge MOSFET \\
Tegangan Masukan & $12 \mathrm{~V} \mathrm{DC}$ \\
Tegangan Keluaran & $220 \mathrm{~V} \mathrm{AC}$ \\
Frekuensi Keluaran & $50 \mathrm{~Hz}$ \\
Sinyal Keluaran & Sinyal Sinusoidal \\
Frekuensi Modulasi & $50 \mathrm{~Hz}$ \\
Frekuensi Penyaklaran & $10,050 \mathrm{~Hz}$ \\
\hline Sumber: Penulis, 2018 &
\end{tabular}

Sumber: Penulis, 2018

Konstruksi MOSFET H-Bridge digunakan dalam inverter karena konfigurasi ini tidak memerlukan dioda atau kapasitor penyeimbang tegangan, berdasarkan bagian 1, sehingga rangkaian inverter disederhanakan. Tegangan masukan yang digunakan adalah $12 \mathrm{~V} \mathrm{DC}$. Hal ini karena tegangan masukan ini merupakan tegangan yang umum digunakan dalam perangkat listrik. Tegangan keluaran $220 \mathrm{~V}$ AC 
dengan gelombang sinus dan frekuensi $50 \mathrm{~Hz}$ dipilih karena merupakan tegangan standar yang digunakan di Indonesia. Frekuensi modulasi yang digunakan adalah $50 \mathrm{~Hz}$ untuk menyesuaikan frekuensi keluaran berdasarkan sub-bagian 1.3.1. Frekuensi penyaklaran $10,050 \mathrm{~Hz}$ dipilih juga berdasarkan sub-bagian 1.3.1 untuk menghindari penurunan tegangan besar pada tegangan keluaran inverter.

\subsection{Diagram Blok Inverter Satu Fasa}

Diagram blok dari inverter satu fasa diperlihatkan pada Gambar 8. Inverter menggunakan sumber tegangan $12 \mathrm{~V}$ DC yang disesuaikan dengan spesifikasi yang ditunjukkan pada Tabel 1. Sumber tegangan DC menjadi sumber energi untuk menjalankan Arduino UNO sebagai pembangkit sinyal SPWM, penggerak MOSFET untuk menjalankan penyaklaran pada H-Bridge MOSFET, dan sebagai masukan ke H-Bridge MOSFET. Sinyal SPWM dihasilkan oleh Arduino UNO yang digunakan untuk mengendalikan saklar pada H-Bridge MOSFET melalui penggerak MOSFET. Rangkaian H-Bridge MOSFET mengubah tegangan $12 \mathrm{~V}$ DC menjadi tegangan $12 \mathrm{~V}$ AC. Tegangan AC yang dihasilkan dari H-Bridge MOSFET dinaikkan menjadi 220V AC menggunakan transformer. Selanjutnya, keluaran transformer difilter dengan menggunakan low pass filter (LPF), sehingga sinyal tegangan keluaran inverter mempunyai sinyal yang mendekati sinusoidal yang dihubungkan ke beban.

\subsection{Penentuan Komponen Penyaklaran Inverter}

MOSFET IRF840 dipilih sebagai komponen penyaklaran untuk H-Bridge MOSFET karena memiliki tegangan gangguan maksimum $500 \mathrm{~V}$ dan frekuensi penyaklaran maksimum $1 \mathrm{MHz}$, yang didasarkan pada datasheet MOSFET IRF840. Tegangan gangguan maksimum $500 \mathrm{~V}$ dianggap sesuai karena $\mathrm{H}$ Bridge MOSFET hanya mengubah tegangan dari $12 \mathrm{~V}$ DC menjadi $12 \mathrm{~V}$ AC, berdasarkan sub-bagian 2.2. Penyaklaran maksimum sebesar $1 \mathrm{MHz}$ juga sesuai karena frekuensi penyaklaran yang digunakan dalam inverter hanya $10,05 \mathrm{kHz}$, berdasarkan sub-bagian 2.1 .

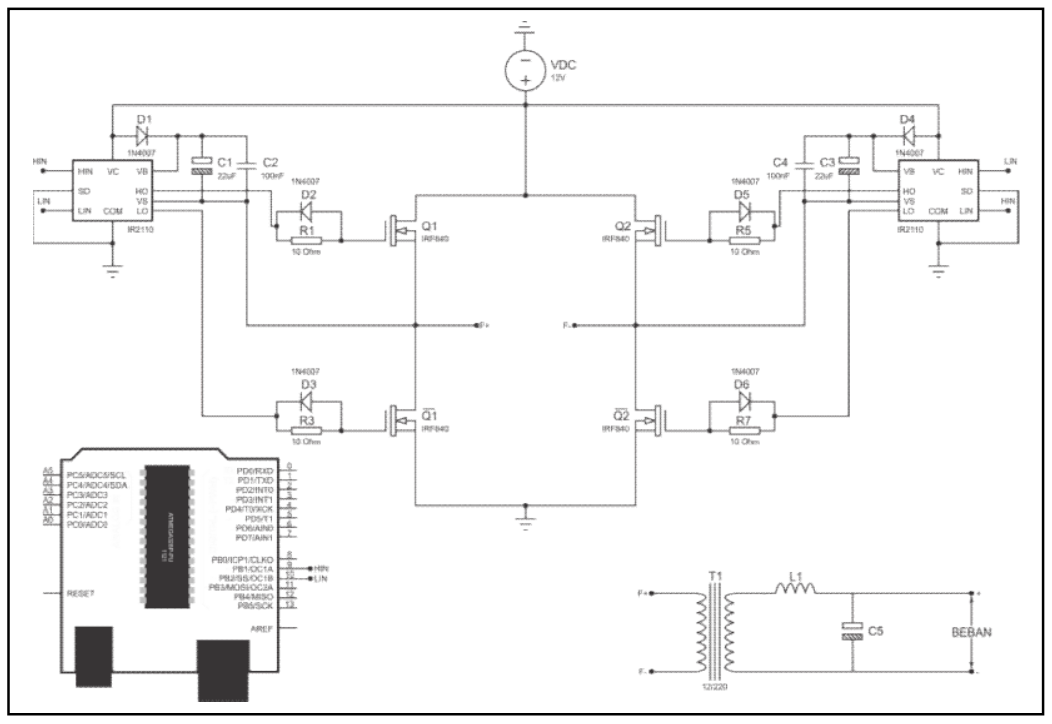

Gambar 9: Desain Rangkaian Inverter Satu Fasa Menggunakan H-Bridge MOSFET Sumber: Penulis, 2018

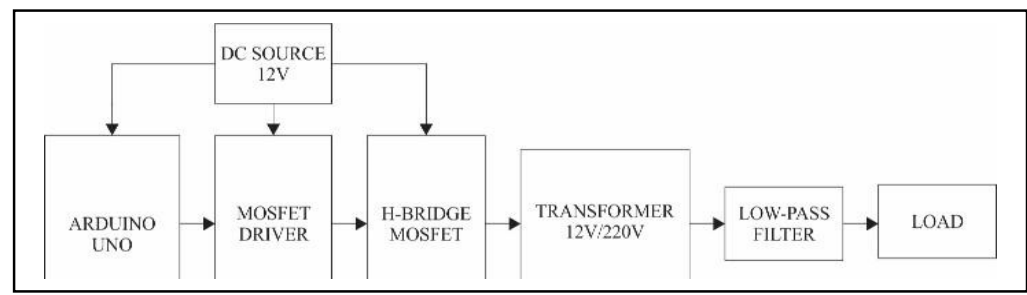

Gambar 8: Diagram Blok Inverter Satu Fasa Sumber: Penulis, 2018 


\subsection{Penentuan Parameter Penggerak MOSFET}

Parameter yang perlu ditentukan dalam driver MOSFET adalah kapasitansi dari kapasitor bootstrap, rating arus dioda bootstrap, dan resistansi dari gerbang resistor. Parameter ini digunakan untuk menentukan komponen yang diperlukan untuk penggerak MOSFET. Untuk memperoleh nilai kapasitansi dari kapasitor bootstrap, maka dapat digunakan persamaan 1. Parameter yang diperlukan untuk menghitung nilai kapasitansi dari kapasitor bootstrap dapat diperoleh baik dari datasheet MOSFET atau datasheet IC penggerak MOSFET.

$$
C \geq \frac{2\left[2 \times 63 \times 10^{-9}+\frac{230 \times 10^{-6}}{10,050}+5 \times 10^{-9}+\frac{250 \times 10^{-6}}{10,050}\right]}{12-0.4-1.2-10}=0.894 \mu \mathrm{F}
$$

Pada sub-bagian 1.2.1, kapasitansi yang diperoleh dalam persamaan 5 perlu dikalikan dengan faktor 15 . Karenanya, kapasitansi minimum untuk kapasitor bootstrap menjadi $0,894 \times 15=13,41 \mu \mathrm{F}$. Karena kapasitor dengan kapasitansi $13.41 \mu \mathrm{F}$ tidak tersedia di pasaran, nilai kapasitansi dari kapasitor bootstrap dinaikkan ke nilai kapasitansi terdekat yang tersedia, yaitu $22 \mu \mathrm{F}$.

Untuk mendapatkan arus rating dari kapasitor bootstrap, dapat digunakan persamaan 2.

$$
I_{\text {diode(rating) }} \geq 63 \times 10^{-9} \times 10,050=0.633 \mathrm{~mA}
$$

Berdasarkan nilai arus yang diperoleh dalam persamaan 6, dioda bootstrap yang digunakan adalah 1N4007, karena berdasarkan datasheet-nya, dioda 1N4007 memiliki nilai arus rata-rata 1A, yang lebih dari nilai yang diperlukan dalam persamaan 6 , dan memiliki tegangan maksimum $1000 \mathrm{~V}$.

Untuk menentukan nilai resistansi dari gerbang resistor, berdasarkan sub-bagian 1.2.3, kurva yang ditunjukkan pada Gambar 4 digunakan. Untuk menghindari lonjakan amplitudo negatif yang tinggi dengan waktu mati yang cukup, resistansi pada gerbang $10 \Omega$ dipilih, sehingga dapat menghasilkan tegangan lonjakan negatif sekitar $35 \mathrm{~V}$ dan waktu mati sekitar $20 \mathrm{~ns}$.

\subsection{Desain Simulasi Inverter}

Simulasi dilakukan menggunakan software Proteus 8.4. Skema dari inverter satu fasa yang dirancang berdasarkan analisis pada sub-bagian 2.1-2.4 ditunjukkan pada Gambar 9. Simulasi kemudian dibuat berdasarkan skema yang ditunjukkan pada Gambar 9. Hasil simulasi menggunakan perangkat lunak Proteus 8.4 kemudian dibandingkan dengan nilai idealnya berdasarkan dari spesifikasi inverter.

\section{Hasil dan diskusi}

Proses simulasi dengan software Proteus 8.4 dilakukan dalam beberapa tahap. Simulasi dimulai dengan mensimulasikan sinyal pembangkit SPWM, diikuti oleh H-Bridge MOSFET, dan LPF. Sebagaimana dijelaskan dalam sub-bagian 2.5, hasil simulasi dibandingkan dengan nilai idealnya berdasarkan dari spesifikasi inverter. Hasil perbandingan digunakan untuk menarik kesimpulan.

\subsection{Simulasi Sinyal Pembangkit SPWM}

Berdasarkan sub-bab 1.3.2, jembatan digital inverter SPWM menggunakan microkontroler untuk menghasikan sinyal SPWM, dalam kasus ini digunakan Arduino UNO. Parameter yang dijelaskan pada sub-bab 2.1 digunakan untuk menghasilkan sinyal SPWM, dimana frekuensi sinyal modulasi yang digunakan adalah $50 \mathrm{~Hz}$ dan frekuensi sinyal pembawa sebesar $10.05 \mathrm{kHz}$. Pada Gambar 10 diperlihatkan sinyal SPWM yang dihubungkan ke saklar $\mathrm{Q}_{1}$ dan saklar $\overline{\mathbf{Q}_{2}}$ atau dapat dilihat sebagai nilai yang tinggi pada inverter. Pada Gambar 11 diperlihatkan sinyal SPWM yang dihubungkan ke saklar $\mathrm{Q}_{2}$ dan saklar $\overline{\mathbf{Q}_{1}}$ atau dapat dilihat sebagai nilai yang rendah pada inverter. Sinyal SPWM yang dihasilkan digunakan untuk menjalankan saklar pada H-Bridge MOSFET yang ada di penggerak MOSFET. Seperti yang dijelaskan pada sub-bab 1.3.2, amplitude dari sinyal SPWM yang dihasilkan memiliki nilai magnitude yang sama dengan tegangan yang bekerja di Arduino UNO, yaitu 5V. 


\subsection{Simulasi H-Bridge MOSFET}

Seperti yang dijelaskan pada sub-bab 3.1, sinyal SPWM yang dihasilkan diperlihatkan pada Gambar 10 dan 11 yang digunakan untuk menjalankan saklar pada H-Bridge MOSFET. Pada Gambar 12 diperlihatkan hasil keluaran berupa tegangan pada H-Bridge MOSFET. Berdasarkan sub-bab 1.3.1, sinyal keluaran tegangan harus memiliki bentuk sinyal yang sama dengan sinyal SPWM dimana memiliki nilai amplitudo puncak ke puncak sebesar $2 V_{\text {DC }}$. Sinyal keluaran tegangan yang diperlihatkan pada Gambar 12 sedikit berebda dengan bentuk sinyal SPWM yang diperlihatkan pada Gambar 10. Perbedaan ini terjadi karena delay waktu kondisi penyaklaran dari nyala ke mati maupun sebaliknya yang terjadi secara kontinyu pada MOSFET yang digunakan.

Berdasarkan spesifikasi pada sub-bab 3.1, sumber tegangan DC yang digunakan sebesar 12V DC. Jadi, nilai amplitudo yang diperlukan sebesar $2 \times 12=24 \mathrm{~V}$. Tegangan keluaran dari H-Bridge MOSFET berhubungan dengan hasil yang diinginkan karena penggunaan amplitudo puncakke pucak sebesar $24 \mathrm{~V}$ sama dengan nilai yang diperhitungkan.

\subsection{Sim ulasi Low Pass Filter (LPF)}

Tegangan keluaran dari H-Bridge MOSFET yang diperlihatkan pada Gambar 12 merupakan masukan untuk transformer. Transformer menaikkan nilai amplitudo tegangan dari $12 \mathrm{~V}$ menjadi $220 \mathrm{~V}$ AC. Tegangan keluaran dari transformer di filter menggunakan filter LC, yang merupakan salah satu jenis LPF, sehingga sinyal tegangan keluaran mendekati bentuk sinyal sinusoidal. Desain dari rangkaian LPF yang digunakan menggunakan metode trial and error. Proses trial and error ini menghasilkan nilai inductor $1 \mathrm{mH}$ dan perubahan nilai kapasitor dari $1 \mu \mathrm{F}-22 \mu \mathrm{F}$. Tabel 2 memperlihatkan hasil simulasi dari filter LC dengan inductor $1 \mathrm{mH}$ dan berbagai jenis kapasitor, sedangkan Gambar 13 memperlihatkan sinyal tegangan keluaran dari berbagai jenis kapasitor.

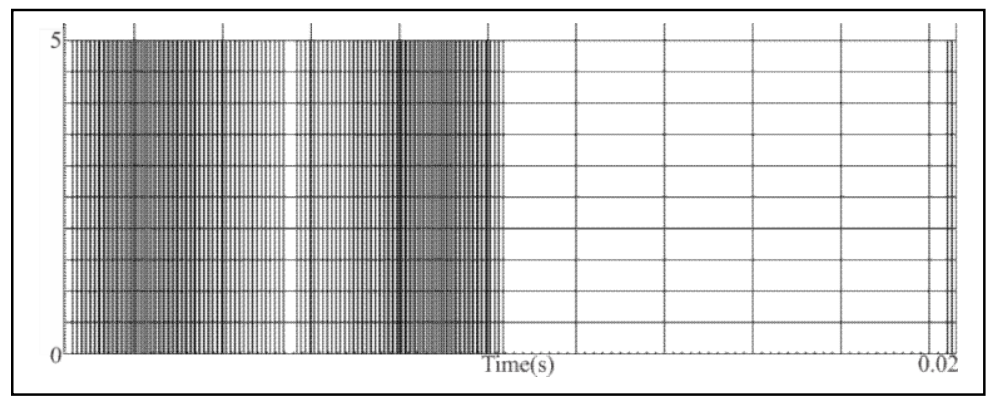

Gambar 10: Sinyal SPWM yang dihasilkan dengan Arduino UNO pada posisi tinggi dari Inverter Sumber: Penulis, 2018

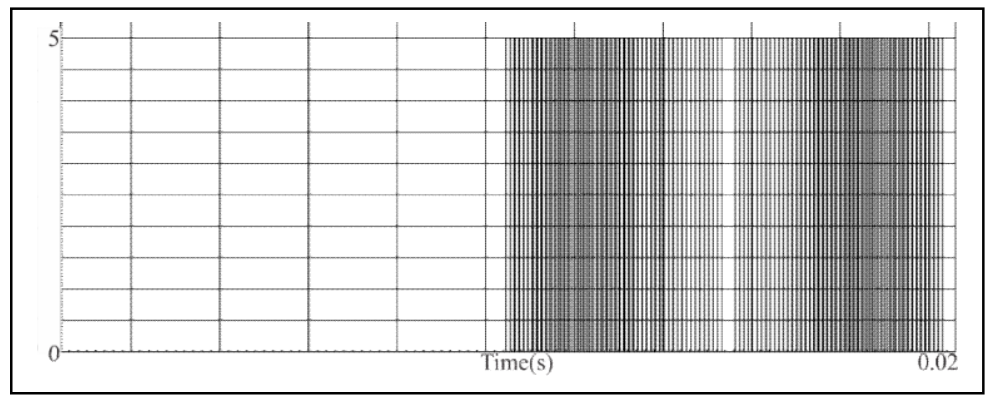

Gambar 11: Sinyal SPWM yang dihasilkan dengan Arduino UNO pada posisi rendah dari Inverter Sumber: Penulis, 2018 


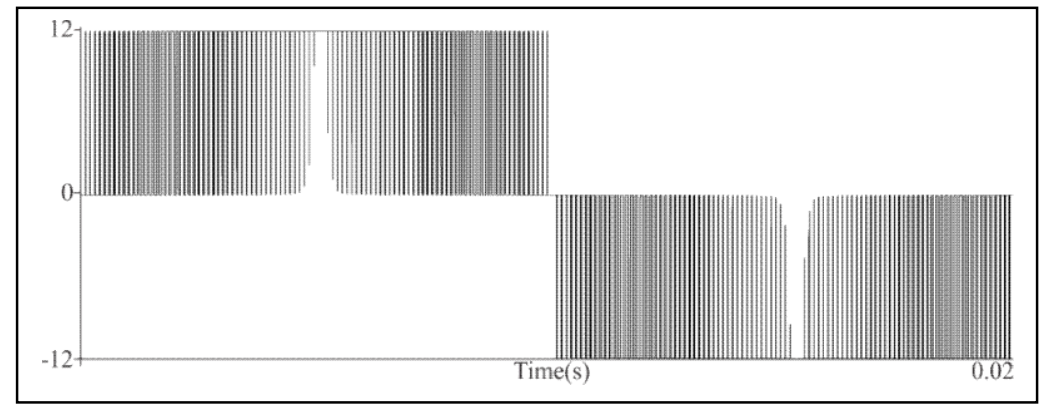

Gambar 12: Tegangan Keluaran dari H-Bridge MOSFET

Sumber: Penulis, 2018

Tabel 2: Hasil Simulasi dari Filter LC Filter dengan induktor $1 \mathrm{mH}$ dan berbagai kapasitor

\begin{tabular}{cccc}
\hline $\mathbf{L}$ & $\mathbf{C}$ & $\boldsymbol{f}_{\boldsymbol{c}}$ & $\mathbf{V}_{\text {keluaran(puncak)) }}$ \\
\hline & $1 \mu \mathrm{F}$ & $5,033 \mathrm{~Hz}$ & $220 \mathrm{~V}$ \\
& $2.2 \mu \mathrm{F}$ & $3,394 \mathrm{~Hz}$ & $220 \mathrm{~V}$ \\
& $3.3 \mu \mathrm{F}$ & $2,771 \mathrm{~Hz}$ & $220 \mathrm{~V}$ \\
$1 \mathrm{mH}$ & $4.7 \mu \mathrm{F}$ & $2,322 \mathrm{~Hz}$ & $217 \mathrm{~V}$ \\
& $10 \mu \mathrm{F}$ & $1,592 \mathrm{~Hz}$ & $179 \mathrm{~V}$ \\
& $22 \mu \mathrm{F}$ & $1,073 \mathrm{~Hz}$ & $103 \mathrm{~V}$ \\
\hline
\end{tabular}

Sumber: Penulis, 2018

Frekuensi cut-off $\left(f_{c}\right)$ dari Tabel 2 dapat diperoleh dengan menggunakan persamaan 4. Pada Tabel 2 diperlihatkan semakin besar nilai kapasitor yang digunakan maka frekuensi cut-off yang digunakan menjadi semakin kecil. Semakin kecil nilai frekuensi cut-off maka nilai tegangan keluaran yang dipotong juga menjadi semakin kecil. Pada Gambar 13 memperlihatkan semakin besar nilai tegangan yang digunakan maka sinyal tegangan keluaran semakin mendekati bentuk sinyal sinusoidal. Hasil dadri simulasi diatas memperlihatkan nilai kapasitor yang paling optimal yaitu $3.3 \mu \mathrm{F}$ karena tegangan keluaran puncak adalah $220 \mathrm{~V}$ dimana sesuai dengan spesifikasi sistem yang diinginkan dan sinyal tegangan keluaran mendekati sinyal sinusoidal.

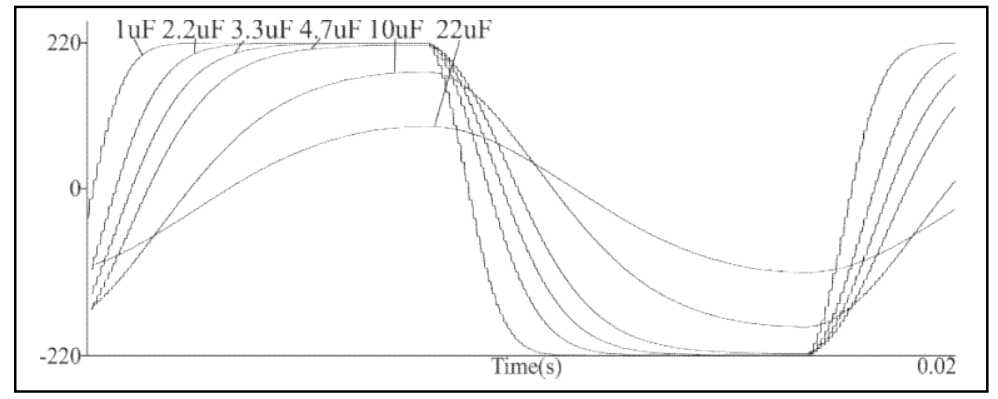

Gambar 13: Sinyal Tegangan Keluaran dari Filter LC menggunakan 1mH dan berbagai Kapasitor Sumber: Penulis, 2018

\subsection{Analisis Tegangan Keluaran Inverter}

Berdasarkan sub-bab 3.3, sinyal tegangan keluaran dari inverter yang didesain diperlihatkan pada Gambar 14. Pada Gambar 14 diperlihatkan tegangan keluaran dari inverter mempunyai amplitudo yang sama dengan spesifikasi yang diinginkan yaitu sebesar 220V AV dan frekuensinya juga sama dengan spesifikasi yang diinginkan sebesar $50 \mathrm{~Hz}$. Tegangan keluaran dari inverter mempunyai sinyal yang mendekati sinyal referensinya, yaitu sinyal sinusoidal. Berdasarkan analisis tersebut, maka inverter satu fasa yang didesain menggunakan rangkaian $\mathrm{H}$-bridge MOSFET memiliki hasil yang sesuai dengan spesifikasi yang disusun pada sub-bab 3.1. 
Desain Inverter Satu Fasa 12V DC ke 220V AC Menggunakan Rangkaian H-Bridge MOSFET

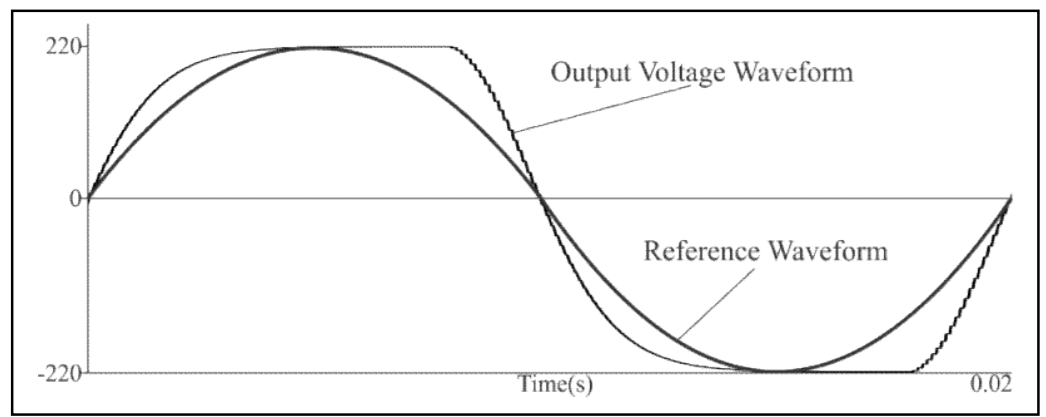

Gambar14: Sinyal Tegangan Keluaran dari Inverter Satu Fasa dengan Rangkaian H-Bridge MOSFET Sumber: Penulis, 2018

\section{Kesimpulan}

Berdasarkan hasil desain inverter satu fasa dengan rangkaian H-Bridge MOSFET maka dapat dipeoleh beberapa kesimpulan, yaitu:

1. The design of single phase inverter was carried out through determining the specification of the inverter step, the making of block diagram step, determining the appropriate switches, calculating the parameters for the MOSFET driver, and creating the circuit schematic.

2. The design of single phase inverter with $\mathrm{H}$-Bridge MOSFET circuit using $12 \mathrm{~V}$ DC voltage source, $50 \mathrm{~Hz}$ modulation signal frequency, and $10.05 \mathrm{kHz}$ carrier signal frequency produces output voltage in accordance to the specifications that have been made, which were the amplitude of $220 \mathrm{~V} \mathrm{AC}$ with $50 \mathrm{~Hz}$ frequency and have the waveform close to the waveform of sine wave.

3. More researches were needed, especially in developing the H-Bridge MOSFET circuit into cascaded H-Bridge MOSFET to increase the level of output voltage and produce a waveform closer to the waveform of sine wave.

\section{Ucapan Terima Kasih}

Penulis ingin berterima kasih kepada orang tua atas dorongan semangat, serta rekan-rekan di Teknik Elektro Institut Teknologi Kalimantan untuk dukungannya. Selain itu, penulis juga ingin berterima kasih untuk semua pihak dalam penyelesaian jurnal ini.

\section{Daftar Pustaka}

Bernard, M. J. (2014) ‘Microcontroller Based Power Inverter’, Project Report, F17/28234/2009.

Meghashree, G. N., Meghana, S., Charishma, C., and Swetha, A. (2016), 'Low Cost Inverter Using H-Bridge to Convert Solar Energy', IJRET: International Journal of Research in Engineering and Technology, Vol. 5, No. 4.

Fairchild. (2014), Design and Application Guide of Bootstrap Circuit for High-Voltage Gate-Drive IC, USA: ON Semiconductor.

Santos, E.C. and Silva, E.R.C. (2015), Advanced Power Electronics Converters PWM Converters Processing AC Voltages, Canada: IEEE Press.

Fadhli, M. R. (2010), Rancang Bangun Inverter $12 \mathrm{~V}$ DC ke 220V AC dengan Frekwensi $50 H z$ dan Gelombang Keluaran Sinusoidal, Indonesia: Universitas Indonesia.

Panggabean, S., Setyawan, F.X.A., and Alam, S. (2017), 'Rancang Bangun Inverter Satu Fasa Menggunakan Teknik High Voltage PWM (Pulse Width Modulation)', ELECTRICIAN - Jurnal Rekayasa dan Teknologi Elektro, Vol. 11, No. 2. 